\title{
Multi-Body Dynamics Analysis of V-Type Diesel Engine Crankshaft
}

\author{
Yanming $\mathrm{Xu}^{*}$, Xianbin Teng, Zhimin Yu and Tao Ge
}

Tianjin Maritime College, Jinnan, Tianjin, 300350, China

\begin{abstract}
Based on the V-type diesel engine crankshaft system, the paper combined the finite element method (fem) and multi-body dynamics method together, made a virtual simulation analysis. First, by $3 \mathrm{~d}$ software and finite element software to establish the multi-body dynamic models of the crankshaft, bearing and piston, then simulated the actual engine working condition, and got the data such as crankshaft acceleration, velocity and displacement by the multi-body dynamics simulation analysis. By calculation, the paper found that by using the combination of finite element and multibody simulation method, can we effectively simulate the diesel engine crankshaft dynamics characteristics.
\end{abstract}

Keywords: Crankshaft, dynamic characteristics, modal reduction, multi-body dynamics.

\section{INTRODUCTION}

Along with the rapid development of modern industry, the oil source is increasingly tense so the working efficiency of diesel engine and life is paid more and more attention. The mechanical strength of diesel engines are also growing. As the core parts of diesel engine, the strength and stiffness of crankshaft has been the research emphasis for the designers. The main method is to analyze the dynamic characteristics of diesel engine crankshaft by effective means of virtual technology and simulation, so as to get multiple kinetic parameters of the crankshaft [1].

The paper is based on a V-type 6 cylinder diesel engine, firstly, to establish flexible model such as crankshaft and bearing by a $3 \mathrm{D}$-design software Pro/E. It adopts the finite element software Altair Hyper to carry out grid control, and then imported into Ansys to pretreatment crankshaft and bearing, to extract parameters such as quality and stiffness matrix, later crankshaft multi-body dynamics simulation by Avl Excite software from Austrian company. The technical route is shown in Fig. (1).

\section{FLEXIBLE MULTI-BODY DYNAMICS MOTION EQUATION}

Diesel engine crankshaft is processed as a flexible body, to establish flexible multi-body dynamics model of the crankshaft. Flexible multi-body dynamics, refers to in a specified inertial reference frame, the system objects' configuration in each time are determined in the inertial reference frame, i.e. to select a moving reference frame for each object in a certain way, the configuration of the object is determined with respect to its own moving reference frame. Avl Excite software establishes the system model using three coordinates, respectively the global coordinate, follow up coordinate, and the son coordinate Fig. (2).
On the analysis of the rigid body plane motion, the complex rigid body plane motion is decomposed into several simple movements. With regard to the motion of flexible body, especially in the case of small deformation, we can also apply a similar approach. For any point $\mathrm{P}$ on the flexible body, the position vector is:

$$
r=r_{0}+A\left(s_{p}+u_{p}\right)
$$

$\mathrm{R}$ is the vector for point $\mathrm{P}$ in the inertial coordinate; $\mathrm{r}_{0} r_{0}$ is the vector for the original point of floating coordinate in inertial coordinate; $\mathrm{A}$ is the direction cosine matrix; $\mathrm{s}_{\mathrm{p}} s_{p}$ is the vector for point $\mathrm{P}$ in floating coordinate before deformation of flexible body; $u_{p}$ is the relative deformation vector, which can be discretized by different methods, for point $\mathrm{P}$, the unit deformation can be described by modal coordinate:

$u_{p}=\varphi_{p} q_{f}$

In the equation above, is the assume deformation modal matrix for point $P$ satisfying the requirement of Leeds base vector, $\mathrm{q}$ is the deformed generalized coordinate [2].

The rate vector and acceleration vector of any point of flexible body can be gotten from first derivative and second derivative:

$$
\begin{aligned}
& \dot{\mathrm{r}}^{P}=\dot{\mathrm{r}}_{0}+\dot{A}\left(s_{p}+u_{p}\right)+A \varphi_{p} \dot{q}_{f} \\
& \ddot{\mathrm{r}}^{P}=\ddot{\mathrm{r}_{0}}+\ddot{A}\left(s_{p}+u_{p}\right)+2 \dot{A} \varphi_{p} \dot{q}_{f}+\varphi_{p} \ddot{q}_{f}
\end{aligned}
$$

The motion equation of flexible body is derived from the following Lagrange equation:

$$
\frac{d}{d t}\left(\frac{\partial L}{\partial \dot{\xi}}\right)-\frac{\partial L}{\partial \xi}+\frac{\partial \tau}{\partial \dot{\xi}}+\left[\frac{\partial \phi}{\partial \xi}\right]^{\tau} \gamma-Q=0
$$




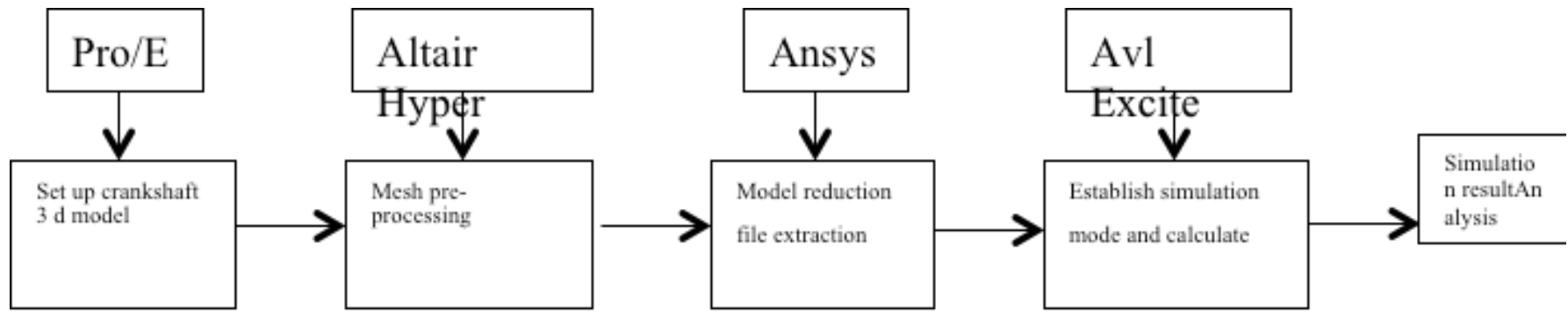

Fig. (1). Ethnical roadmap.

$\phi=0$

In the equation above, $\phi$ is the constraint equation; $\gamma$ is the corresponding constraint equation of Laplace multiplier; $\xi \quad \xi$ is the defined generalized coordinate; $Q$ is the generalized force projected on $\xi \xi$; $\mathrm{L}$ is Lagrange item, defined as $\mathrm{L}=\mathrm{T}-\mathrm{W}, \mathrm{T}$ and $\mathrm{W}$ are kinetic energy and potential energy respectively; $\tau$ expresses energy loss function.

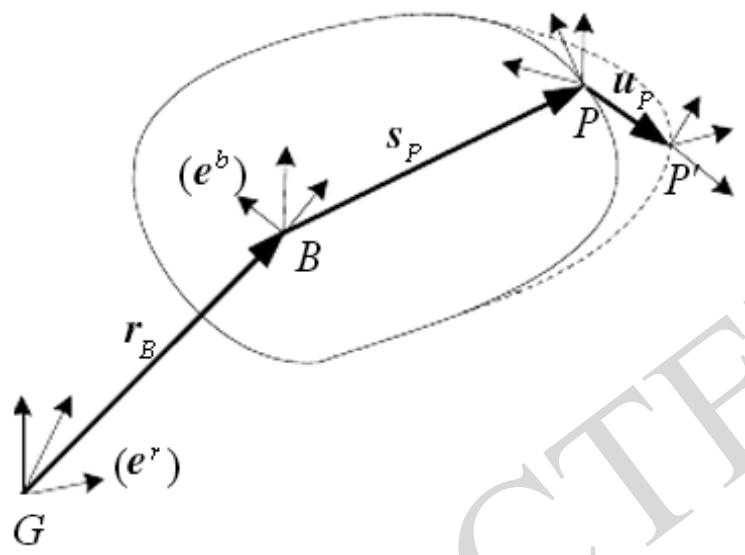

Fig. (2). Deformation Model of Flexible Body.

\section{MULTI-BODY DYNAMIC MODEL OF THE CRANKSHAFT}

\subsection{Diesel Engine Technical Parameters}

Taking a V-type marine diesel engine as the research object, the detailed parameters are shown in Table 1.

Table 1. Main Performance And Technical Parameters of Diesel Engine.

\begin{tabular}{|c|c|}
\hline Item & Index \\
\hline \hline Number of stroke/number of cylinder & $4 / 6$ \\
\hline V shaped angle & $120^{\circ}$ \\
\hline Way of air inlet & naturally aspirated \\
\hline Cooling method & forced water cooling \\
\hline Fire sequence & $1-6-5-4-3-2$ \\
\hline Rated speed & $3750 \mathrm{r} / \mathrm{min}$ \\
\hline
\end{tabular}

3.2. Model Establishment and the Meshing of the Crankshaft
To build three-dimensional model of the parts according to the detailed geometry in diesel engine design drawings, in the simulation analysis, dynamic characteristic analysis only on the crankshaft and bearing in the system, therefore, the three-dimensional model of the two components is established. In the simulation analysis, parts such as cylinder, connecting rod, gudgeon pin, flywheel and damper, are replaced by virtual parts. The crankshaft $3 \mathrm{~d}$ graphics are shown in Fig. (3).

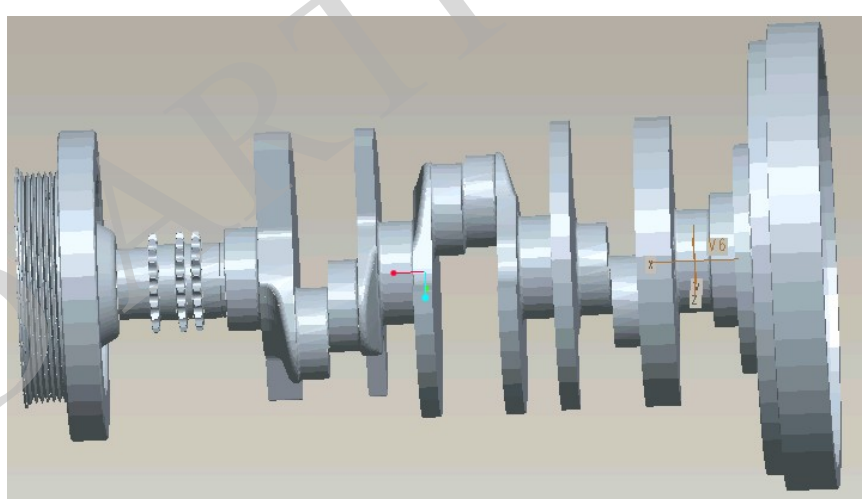

Fig. (3). Three D model of crankshaft.

\subsection{Model Reduction}

In finite element analysis, $3 \mathrm{~d}$ model needs meshing, and then the modal reduction can be preceded. To establish the spider grid structure, for better modal reduction, the meshing quality request for crankshaft main journal and crank pin journal is relatively high. In a variety of finite element software, the Altair Hyper software pre-processing meshing control is better. Model uses the six-side solid45 unit to mesh, first for main journal, and then based on the meshing to process the crank pin journal, it is important to note that it needs seamless joint of the main journal and crank pin journal connecting the crank journal grid, as shown in Fig. (4). The meshing of the crank pin can use 4 sides soild 45 units [3].

After meshing, the crankshaft will produce tens of thousands of freedom degrees, in the process of computing simulation, the result is too big. Modal reduction is to reduce the thousands of freedom degrees to several hundred, which greatly reduces the computing workload. In reduction process, define the primary freedom, to make it have the same dynamic characteristics with the original structure model. The general method is the main journal defines five DOF nodes, crank pin journal defines 1 DOF nodes, each DOF node has six degrees of freedom (UX, UY, UZ, ROTX, ROTY, ROTZ), in the end, the total number of degree of 
freedom $=$ number of DOF node + number of modal degree of freedom. Main bearing model reduction can be done on the basis of the crankshaft Fig. (5).

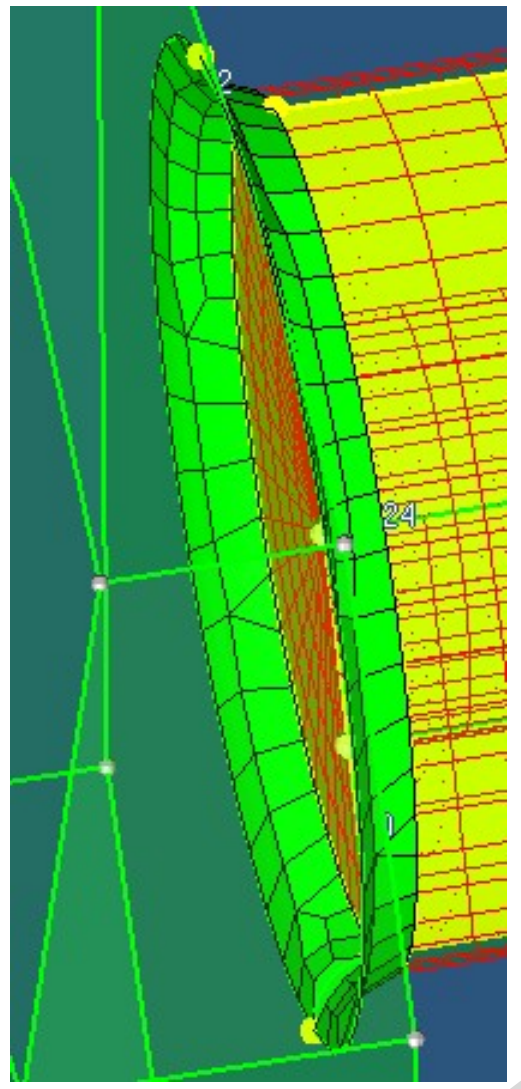

Fig. (4). Grid docking of journal and crank pin.

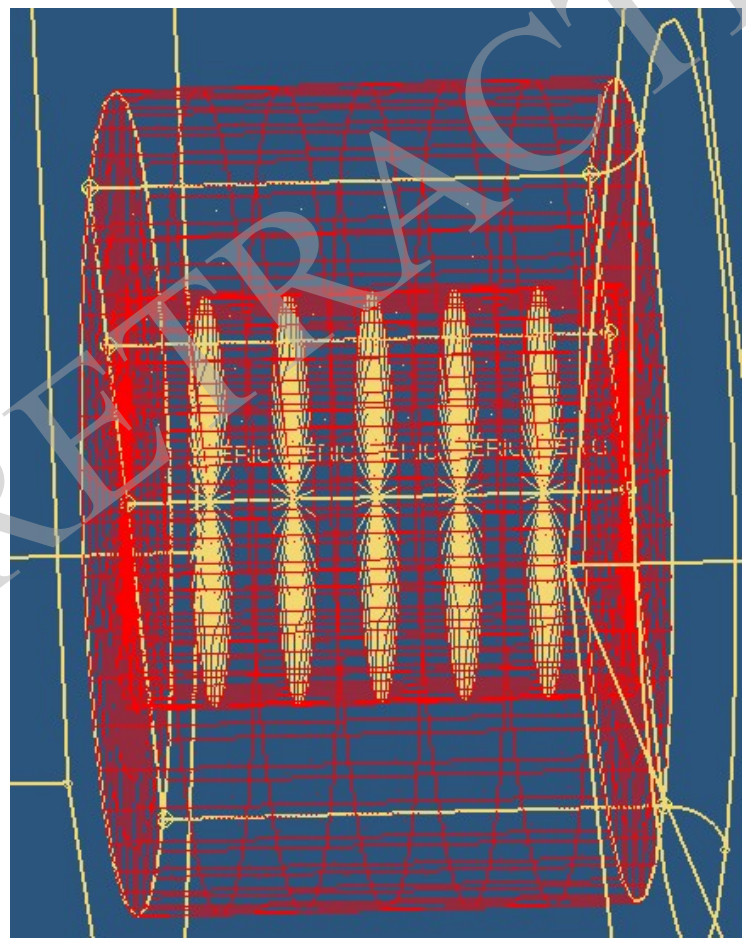

Fig. (5). Spider structure of crankshaft journal.

In Altair Hyper software, after the pretreatment of modal reduction to crankshaft and bearing, import it into Ansys for modal reduction. Crankshaft unit type is CON6, modal order number positions at 10 . After reduction, the following results file is achieved, respectively: master files of degrees of freedom (*.DOFT), geometric files (*.GOEM), mass matrix and stiffness matrix (*.OUT4), and the element stiffness matrix (*.KDIC, *.KELM), for the use of latter simulation calculation Fig. (6).

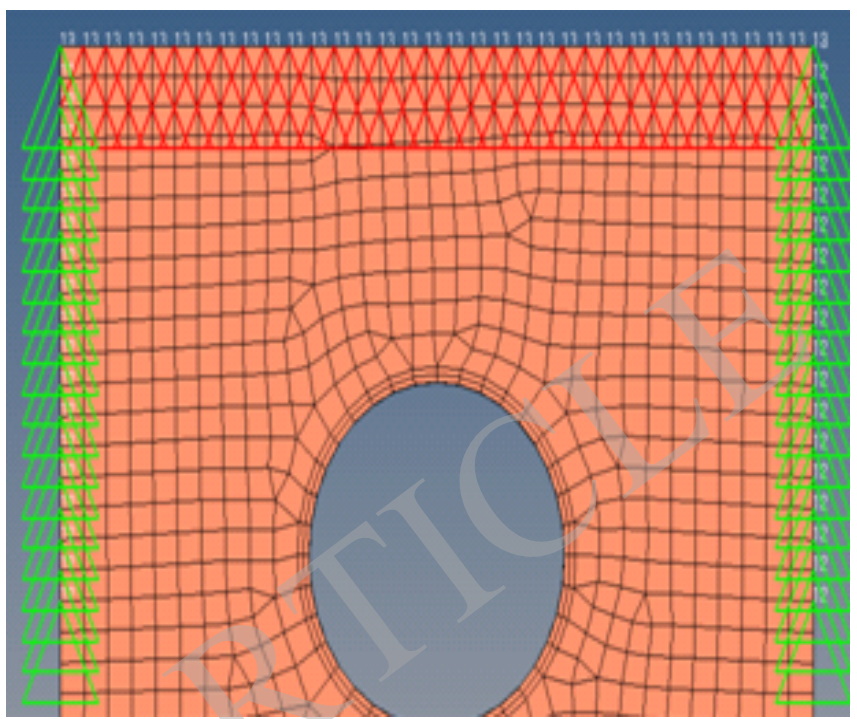

Fig. (6). Bearing constraint model.

Avl Excite software in multi-body dynamics analysis of diesel engine is professional to some extent, which is advanced simulation software of diesel engines. After the above treatment, the paper establishes dynamic simulation models of the V-diesel engine crankshaft system in Avl Excite [4]. As shown in Fig. (7).

With the model completed above and importing related parameters, the connecting rod generates model automatically by software based on the related data. All parts are connected by corresponding nodes, to establish mutual coupling relationships. The coupling 3D model after reducing is shown in Fig. (8).

\section{SIMULATION RESULTS AND ANALYSIS}

The simulation calculation aims diesel engine rated speed as the research object, selects the $3750 \mathrm{r} / \mathrm{min}$ cylinder pressure curve as the input of diesel engine multi-body dynamics calculation, the results set for the crankshaft and bearing force and torque as output results. Gas force loads on the connecting rod small quality node, the cylinder pressure curve as shown in Fig. (9). Calculation results removes the first and second cycle of diesel unstable operation, the third cycle (crank angle is $1440^{\circ}$ ) as the starting point, to get the crankshaft and bearing force and displacement [5].

\subsection{Crankshaft Dynamics Analysis}

In the simulation calculation results, the overall crankshaft displacement curves, velocity curves, acceleration curves are extracted to illustrate the dynamic characteristics of crankshaft. 


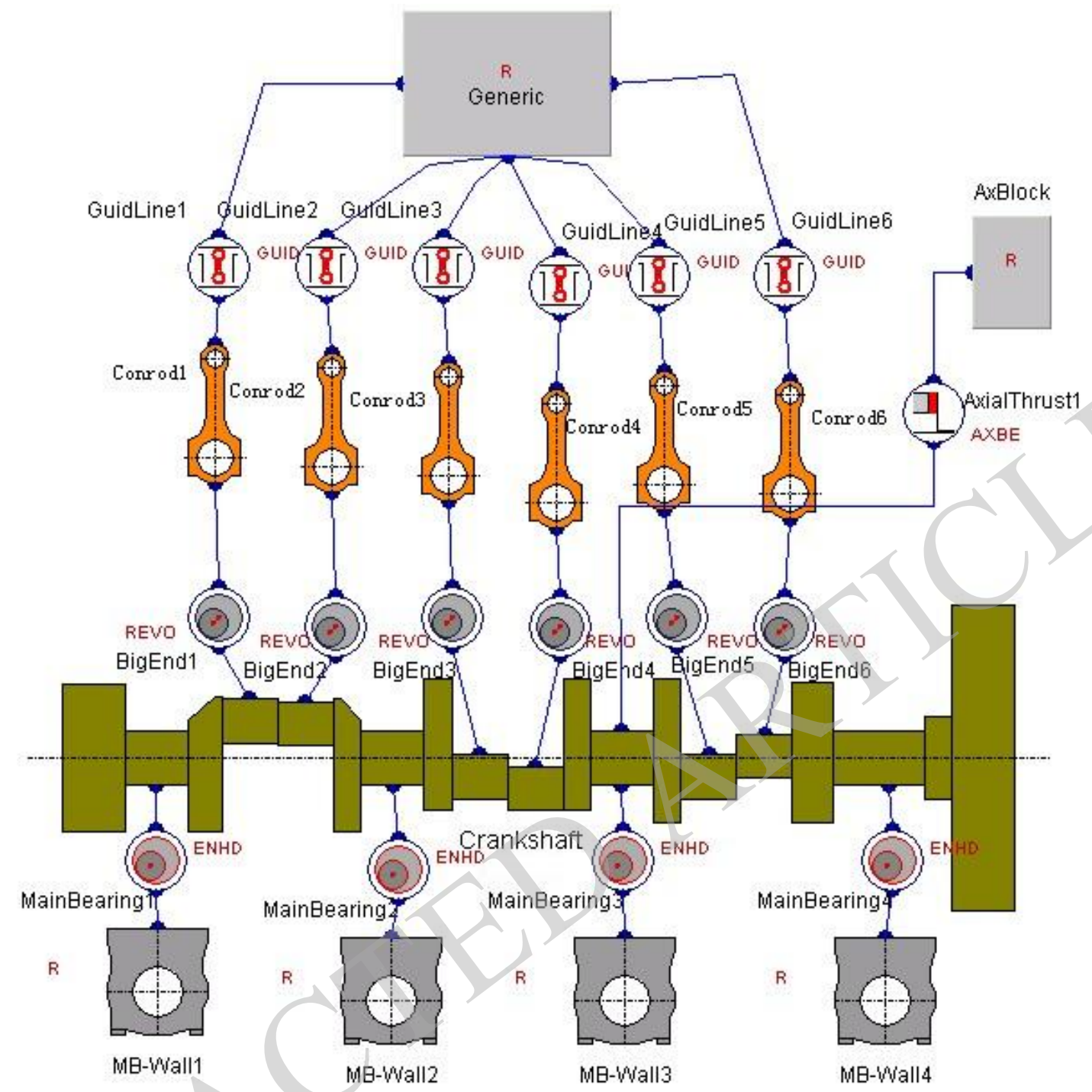

Fig. (7). Multi-body dynamic model of diesel engine.

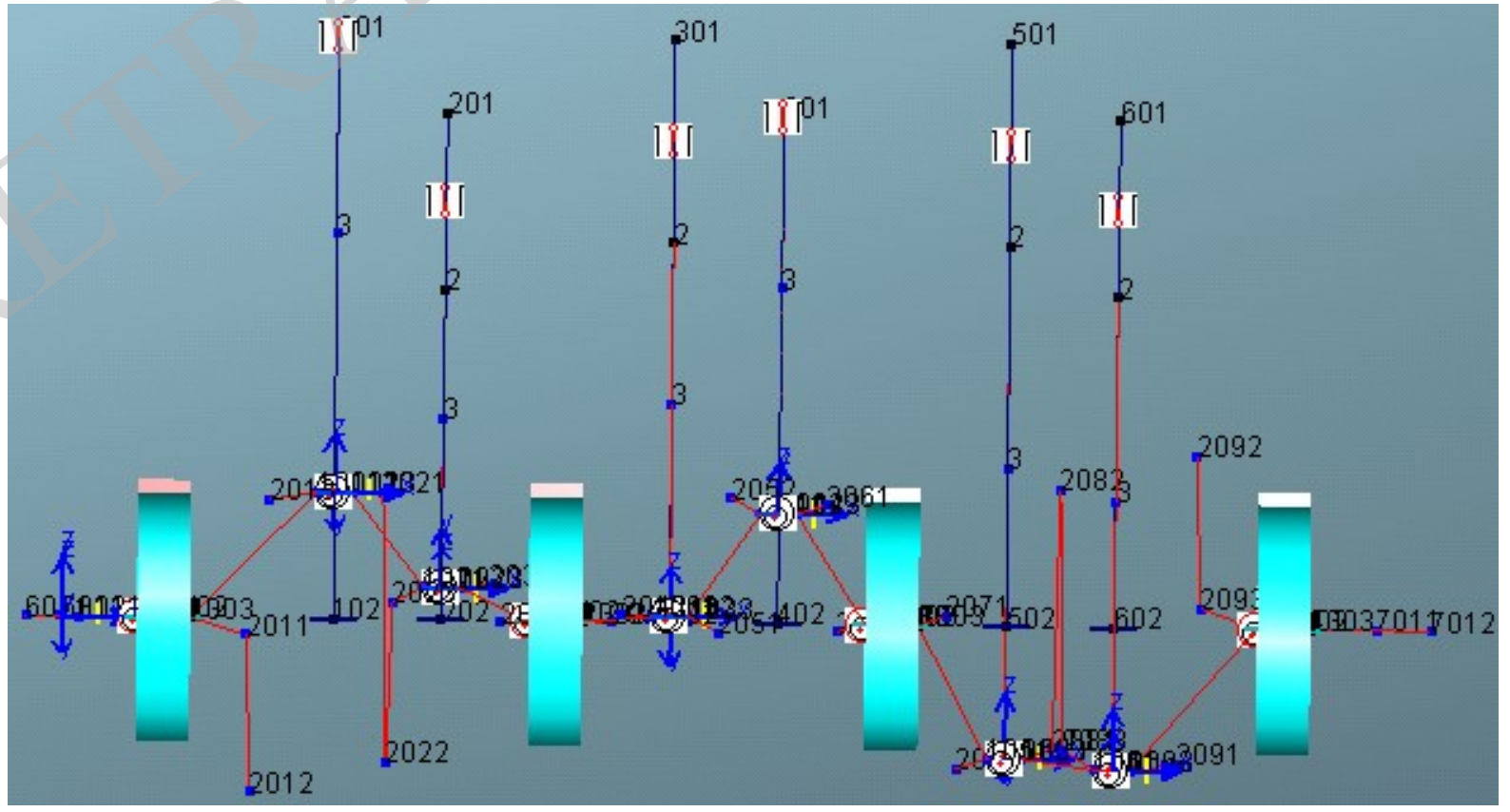

Fig. (8). Reduced model of the multi body dynamics. 


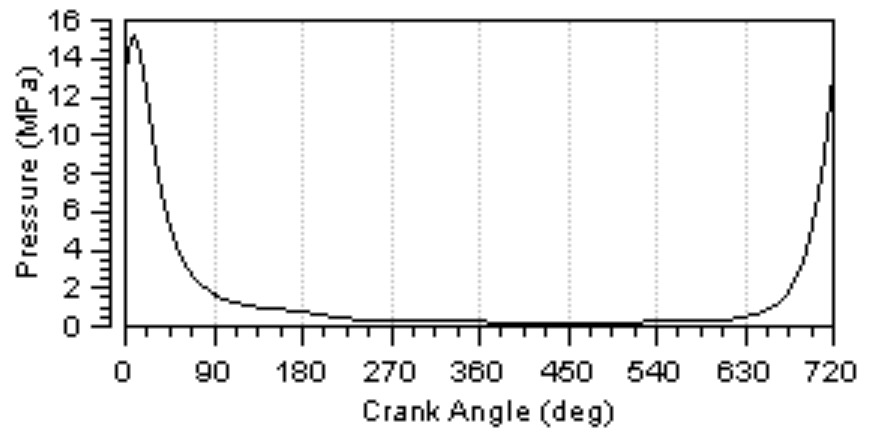

Fig. (9). Diesel engine cylinder pressure curve.

Figs. $(\mathbf{1 0}, \mathbf{1 1})$ are for crankshaft speed and acceleration curve, with the diesel engine start working, in the vertical direction and a third direction, wave velocity and acceleration of the crankshaft is obvious, the ignition TDC is the maximum, and then began to decrease. Therefore, in this process, because of the change of diesel engine crankshaft, an unsmooth running is prone to happen, higher requirements to the performance of diesel engine [6-8].
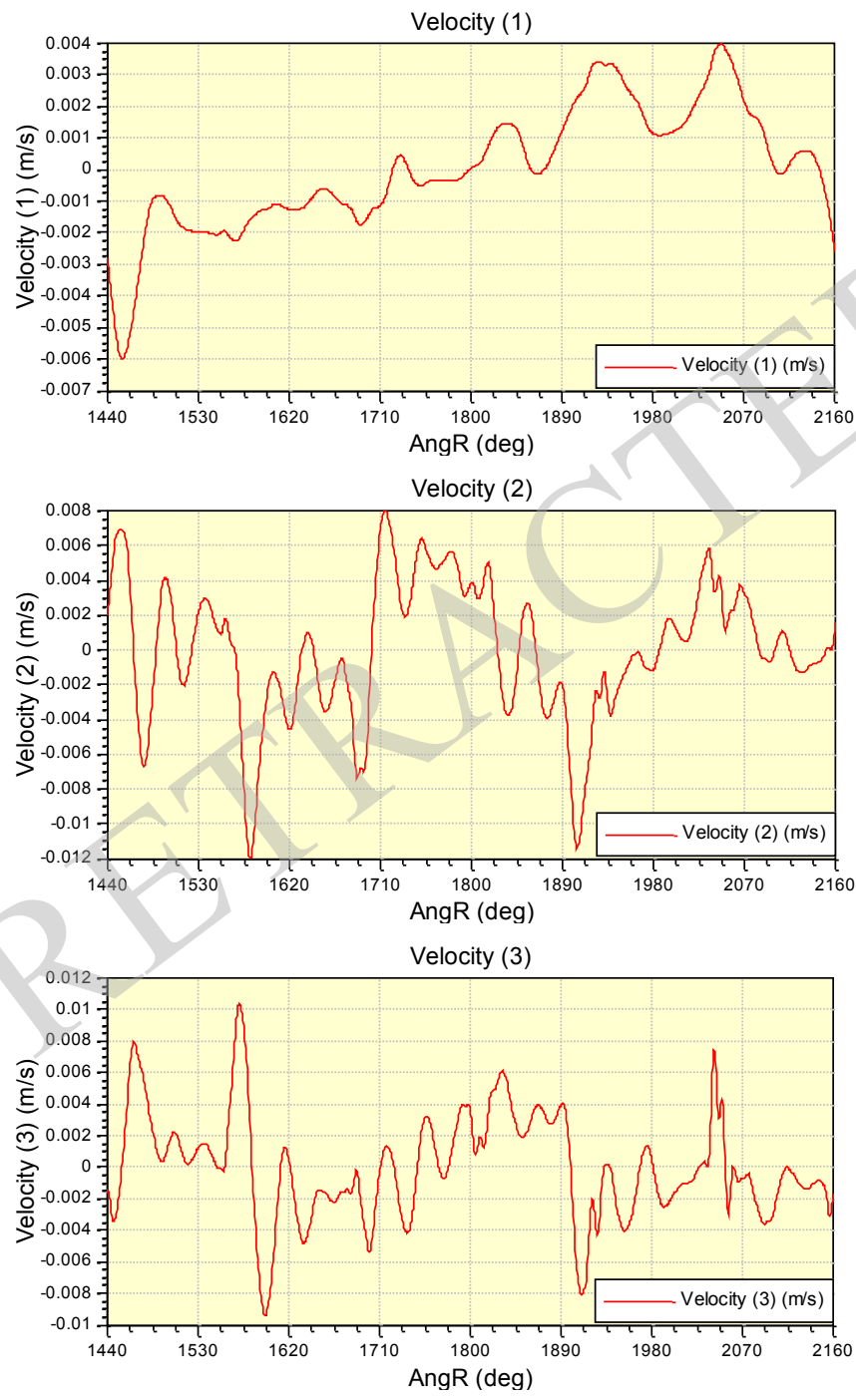

Fig. (10). The Crankshaft Speed Curve.
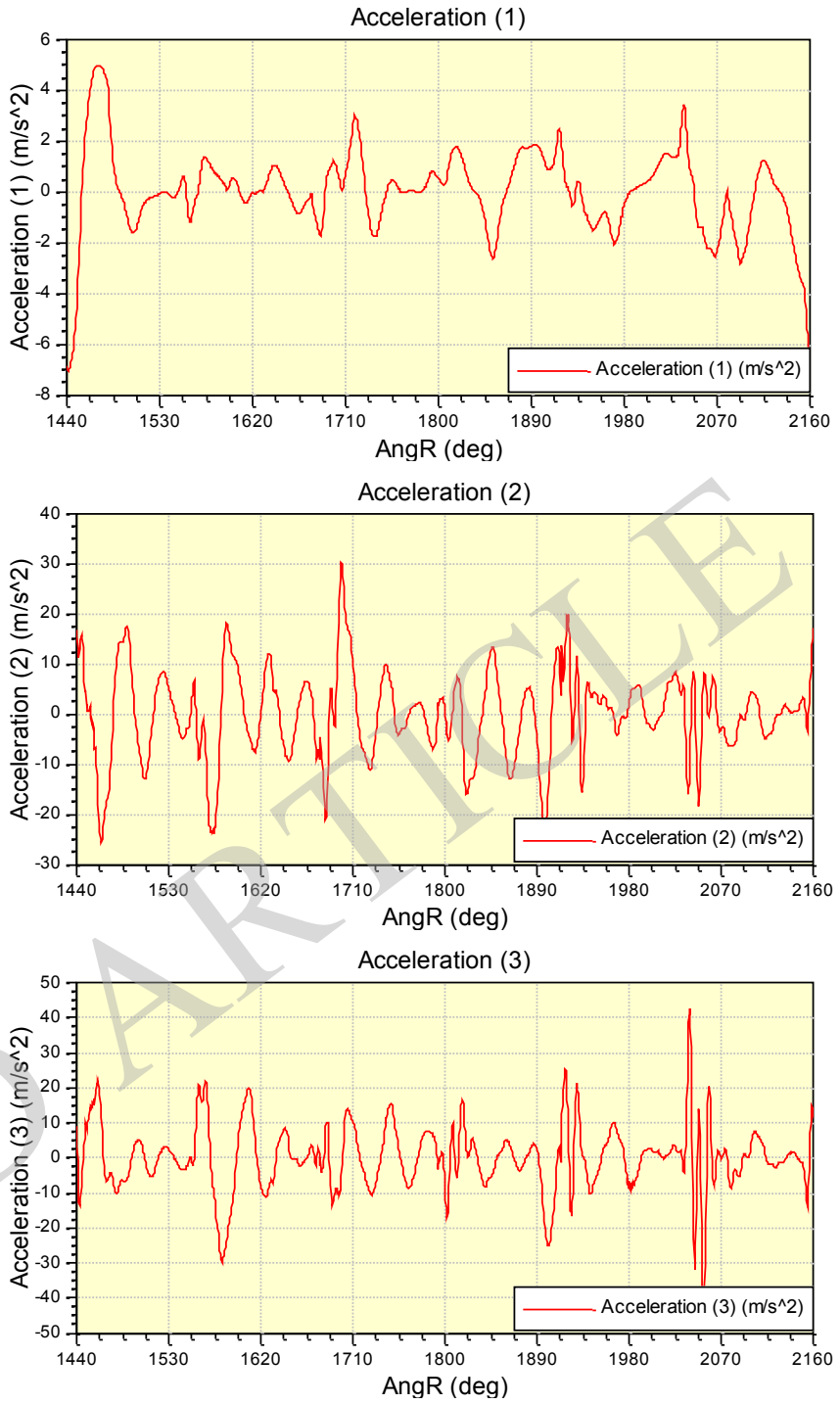

Fig. (11). Crankshaft Acceleration Curve.

\subsection{Dynamics Analysis of Spindle Bearing}

The applied load on the main bearing together with combustion pressure, piston connecting rod inertia force, is the most important excitation source of diesel engine vibration and noise, therefore, research of main bearing is very necessary. Fig. (12) gives diesel engine crankshaft 4 stress results of main bearing in vertical direction and third direction. It is found that the curve peak is generally the pressure outbreak of diesel engine adjacent cylinders, the work load of the first main bearing is the minimum, while the second main bearing the maximum [9].

\section{CONCLUSION}

In the process of diesel engine operation, attention should be paid to the instability phenomenon, at the same time to the wears of diesel engine main bearing. Through the multibody dynamics simulation of crankshaft and bearing seat, the force and vibration conditions of diesel engine crankshaft 

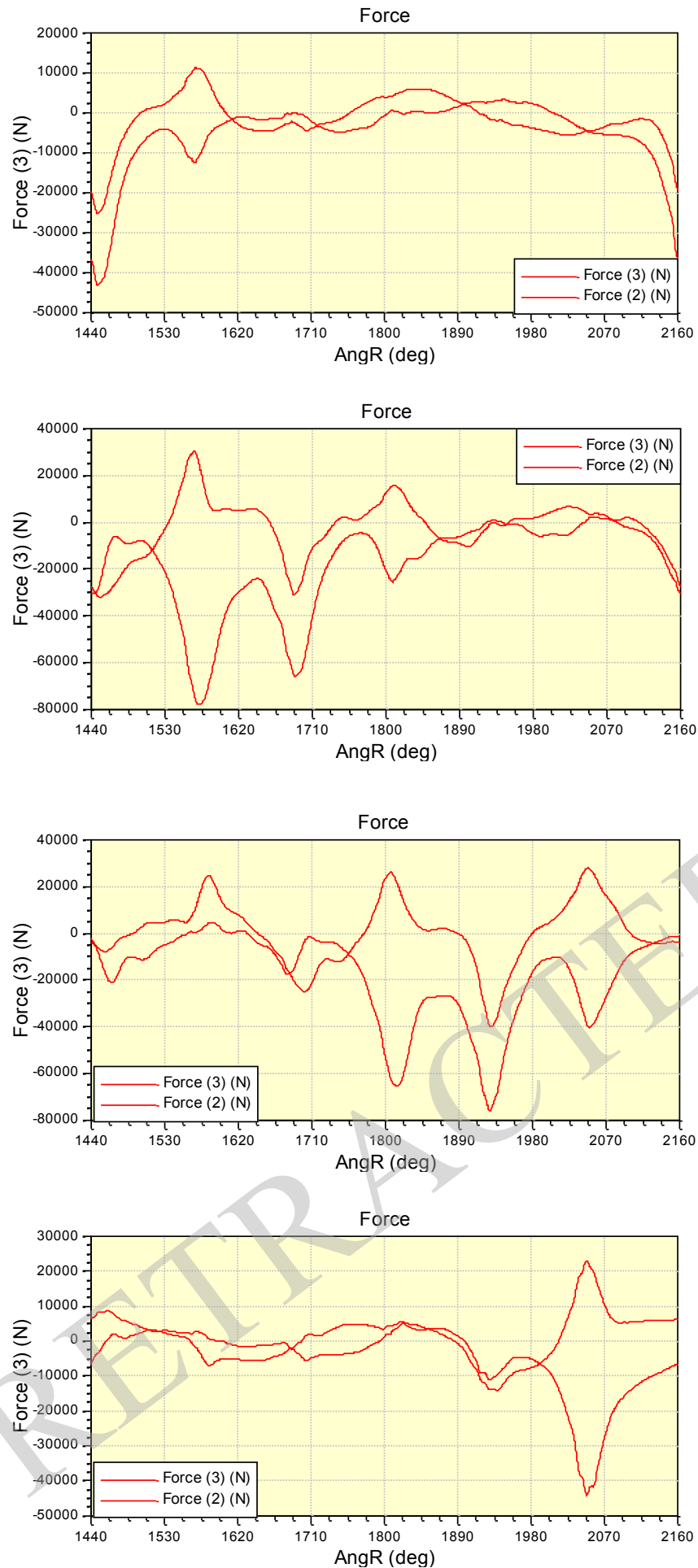

system are fitted better, more in line with the actual diesel engine operation condition. Multiple finite element soft wares are used flexibly, combining with the multi-body dynamics method, is the trend of future dynamics simulation of diesel engines.

\section{CONFLICT OF INTEREST}

The authors confirm that this article content has no conflict of interest.

\section{ACKNOWLEDGEMENTS}

This work is partially supported by Tianjin Municipal Science and Technology Commission of University Development Fund Project (Grant no. 20110425).

\section{REFERENCES}

[1] P. Ding, and C. Wu, "The review \& prospect of the development of computational methods of diesel engine crankshaft", Chinese Internet Combustion Engine Engineering, vol. 24, no. 3, pp. 74-79, 2003.

[2] G. Zhang, B. Huang, G. Pu, et al. "Crankshaft fatigue life calculation based on dynamic simulation and FEA", Chinese Internet Combustion Engine Engineering, vol. 27, no. 1, pp. 41-44, 2006.

[3] Y. Huang, H. Gao, and P. Liu, "Analysis of fatigue strength and life of diesel crankshaft based on multi-body dynamics", Journal of Naval University of Engineering, vol. 24, no. 5, pp. 54-57, 81, 2012 Y. Huang, H. Gao, and G. Kang, "Research on cylinder scuffing characteristic of diesel engine by multi-body dynamics method", Small Internal Combustion Engine and Motorcycle, vol. 41, no. 6, pp. 17-19, 2012

[5] X. Deng, and B. Zhang. "Analysis of crankshaft system in internal combustion engines based on multi-body system dynamics", Mechanical Research \& Application, 2012

[6] Y. Qiu, M. Xu, and M. Li, "Investigation on lubrication characteristics of main bearings in gasoliine engine based on multibody dynamic and kriging modeling", Machine Design and Research, vol. 28, no. 3, pp. 44-50, 2012

[7] M.T. Ma, and I.R.W. McLuckie, "An EHD study of a connecting rod big end bearing including elasticity and inertia effects of the bearing structure," Tribology Series, vol. 43, pp. 313-327, 2003.

[8] L. Wei, S. Duan, Q. Wu, J. Wu, and H. Yu, "Numerical simulation of connecting- rod mechanism coupled nonlinearly with engine", Journal of Dalian Maritime University, vol. 38, no. 1, pp. 89-93, 2012

[9] G. Bayada, S. Martin, and C. Vazquez, "An average flow model of the reynolds roughness including a mass- flow preserving cavitations model", Journal of Tribology, vol. 127, pp. 793-802, 2005 .

Fig. (12). The results of the force for crankshaft main bearing.

(C) Xu et al.; Licensee Bentham Open.

This is an open access article licensed under the terms of the Creative Commons Attribution Non-Commercial License (http://creativecommons.org/licenses/by-nc/3.0/) which permits unrestricted, non-commercial use, distribution and reproduction in any medium, provided the work is properly cited. 